\title{
Supporting Information: Unraveling the ion adsorption kinetics in microporous carbon electrodes: a multi-scale quantum-continuum simulation and experimental approach
}

Diego I. Oyarzun ${ }^{\mathrm{a}, 1}$, Cheng Zhan ${ }^{\mathrm{a}, 1}$, Maira R. Ceron ${ }^{\mathrm{a}}$, Helen A Kuo ${ }^{\mathrm{a}}$, Steven A. Hawks ${ }^{\mathrm{a}}$, Colin K. Loeb $^{\mathrm{a}}$, Fikret Aydin ${ }^{\mathrm{a}}$, Tuan Anh Pham ${ }^{\mathrm{a}^{*}}$, Michael Stadermann ${ }^{\mathrm{a}^{*}}$, and Patrick G. Campbell ${ }^{*}$

${ }^{a}$ Lawrence Livermore National Laboratory, 7000 East Avenue, Livermore, CA 94550, USA

* Corresponding author

${ }^{1}$ Equal contribution

\begin{abstract}
This supporting information document provides additional descriptions and results. Included are: the complete mathematical formulation of the multispecies dynamic model with kinetics; the complete list of parameters utilized in the numerical model; the numerical predictions with a $\mathrm{mD}$ model; the HCAM material characterization; UV-vis data acquisition experimental setup; and 2D potential energy surface plots from DFT simulations.
\end{abstract}

\section{S1 Continuum model with kinetics}

In this section, we describe the complete formulation for the multispecies dynamic model with kinetics. We apply a well-mixed reactor approach to model the system, the mass balance for the specie $i$ is given by

$$
V_{\text {cell }} \frac{d c_{i}}{d t}=Q\left(c_{\mathrm{feed}, i}-c_{i}\right)-V_{\mathrm{mi}}\left(\frac{d c_{\mathrm{mi}, i, A}}{d t}+\frac{d c_{\mathrm{mi}, i, C}}{d t}\right)
$$

where $V_{\text {cell }}$ is the cell volume, $Q$ is the flow rate, $c_{\text {feed, } i}$ is the feed concentration of ion $i, c_{i}$ is the effluent concentration of the ion $i$ and the concentration inside the cell (under the well mixed reactor assumption), and $V_{\mathrm{mi}}$ is the micropore volume. Finally, $c_{\mathrm{mi}, i, A}$ and $c_{\mathrm{mi}, i, C}$ are the micropore concentration for ion $i$ at the anode (subscript $A$ ) and cathode (subscript $C$ ), respectively. Eq $\mathrm{S} 1$ is used to model $i-1$ species, the last $i^{\text {th }}$ specie is calculated with net neutrality. The micropore concentration terms are derived from the first order kinetic model, derived in the main text, as in,

$$
\begin{array}{ll}
\frac{d c_{\mathrm{mi}, i, A}}{d t}=k_{\mathrm{on}, i, A} \exp \left(-(1-\beta) z_{i} \phi_{D, A}\right) c_{i}-k_{\mathrm{off}, i, A} \exp \left(-\beta z_{i} \phi_{D, A}\right) c_{\mathrm{mi}, i, A}, & \text { eq. S2 } \\
\frac{d c_{\mathrm{mi}, i, C}}{d t}=k_{\mathrm{on}, i, C} \exp \left(-(1-\beta) z_{i} \phi_{D, C}\right) c_{i}-k_{\mathrm{off}, i, A} \exp \left(-\beta z_{i} \phi_{D, C}\right) c_{\mathrm{mi}, i, C}, & \text { eq. S3 }
\end{array}
$$


where $z_{i}$ is the valence of the ion $i, \beta$ is the symmetry factor, $\phi_{D, A}$ is the potential inside the micropore at the anode, and $\phi_{D, C}$ is the potential at the cathode. $k_{\mathrm{on}, i, A}$ and $k_{\mathrm{on}, i, C}$ are the rate constants for the ion $i$ transporting from solution to the pore. Similarly, $k_{\mathrm{off}, i, A}$ and $k_{\mathrm{off}, i, C}$ are the rate constants for the ion $i$ for the ion travelling from the pore to solution. The rate constants are calculated from the Arrhenius equation as described in the main text.

Next, we use Kirchhoff's voltage law to relate the external bias $V_{\text {ext }}$ and current $I_{\text {ext }}$ to the potential drop inside the micropores $\left(\phi_{D, A}\right.$ and $\left.\phi_{D, C}\right)$, and electric stern layers $\left(\phi_{S t, A}\right.$ and $\left.\phi_{S t, C}\right)$, which is given by,

$$
\frac{V_{\mathrm{ext}}(t)}{V_{t h}}=\frac{I_{\mathrm{ext}} R_{s}}{V_{t h}}-\left(\phi_{S t, A}+\phi_{D, A}\right)+\left(\phi_{S t, C}+\phi_{D, C}\right),
$$

where $R_{S}$ is the series resistance of the cell and $V_{t h}$ is the thermal voltage. Then, the stern potential is related to the stern capacitance, $C_{S t}$, and the electronic charge, for the cathode and anode we obtain,

$$
\begin{aligned}
\sigma_{\text {elec }, A} & =C_{S t} V_{t h} \phi_{S t, A}, \\
\sigma_{\text {elec }, C} & =C_{S t} V_{t h} \phi_{S t, C},
\end{aligned}
$$

where $\sigma_{\mathrm{elec}, A}$ and $\sigma_{\mathrm{elec}, C}$ are the electronic charge in the anode and cathode, respectively. The ionic charge in the micropores is determined by,

$$
\begin{aligned}
\sigma_{\text {ionic }, A} & =F \sum_{i} z_{i} c_{\mathrm{mi}, A}, \\
\sigma_{\text {ionic }, C} & =F \sum_{i} z_{i} c_{\mathrm{mi}, C} .
\end{aligned}
$$

The ionic currents and the electronic currents are related by

$$
\begin{aligned}
& \sigma_{\text {ionic }, C}+\sigma_{\text {elec }, C}=0 \\
& \sigma_{\text {ionic }, A}+\sigma_{\text {elec }, A}=0
\end{aligned}
$$

Then, we invoke current conservation at the anode and cathode as in,

$$
\sigma_{\mathrm{elec}, A}=\sigma_{\mathrm{elec}, C}
$$

Finally, we relate the external current to the electronic charge as, 


$$
I_{\mathrm{ext}}=V_{\mathrm{mi}} \frac{d \sigma_{\mathrm{elec}, A}}{d t}
$$

\section{S2 Kinetics parameters in the simulation}

To combine the kinetics parameters with the DFT derived quantities, we normalized the $\mathrm{NO}_{3}{ }^{-}, \mathrm{Cl}^{-}$, and $\mathrm{Na}^{+}$(on and off) rate constants by the on and off $\mathrm{Cl}^{-}$rate constants, respectively. After normalization, the ratios (on and off) between $\mathrm{NO}_{3}{ }^{-}$and $\mathrm{Cl}^{-}$rate constants were calculated from the Arrhenius equation. Assuming equal on and off prefactors $A$, we obtain

$$
\begin{aligned}
& r_{\mathrm{on}, N O_{3}^{-}}=\frac{A_{\text {on }} \exp \left(-E_{\mathrm{a}, \mathrm{on}, N O_{3}^{-}} / k T\right)}{A_{\mathrm{on}} \exp \left(-E_{\mathrm{a}, \mathrm{on}, C l^{-}} / k T\right)}, \\
& r_{\mathrm{off}, N O_{3}^{-}}=\frac{A_{\mathrm{off}} \exp \left(-E_{\mathrm{a}, \mathrm{off}, N O_{3}^{-}} / k T\right)}{A_{\mathrm{off}} \exp \left(-E_{\mathrm{a}, \mathrm{off}, \mathrm{Cl}} / k T\right)},
\end{aligned}
$$

where $r_{\mathrm{on}, \mathrm{NO}_{3}^{-}}$and $r_{\mathrm{off}, \mathrm{NO}_{3}^{-}}$are the normalized ratios of the on and off $\mathrm{NO}_{3}{ }^{-}$rate constants. Table

\begin{tabular}{|c|c|c|c|c|c|c|}
\hline $\begin{array}{c}\text { Pore size, } \\
\dot{A}\end{array}$ & $\begin{array}{l}E_{\mathrm{a}, \mathrm{on}, \mathrm{N} O_{3}^{-}} \\
\mathrm{kcal} / \mathrm{mol}\end{array}$ & $\begin{array}{c}E_{\mathrm{a}, \mathrm{on}, C l^{-}} \\
\mathrm{kcal} / \mathrm{mol}\end{array}$ & $\begin{array}{c}\Delta H_{N O_{3}^{-}} \\
\mathrm{kcal} / \mathrm{mol}\end{array}$ & $\begin{array}{c}\Delta H_{C l^{-}} \\
\mathrm{kcal} / \mathrm{mol}\end{array}$ & $r_{\mathrm{on}, N O_{3}^{-}}$ & $r_{\text {off }, N O_{3}^{-}}$ \\
\hline 6 & 3.16 & 10.87 & 2.52 & 8.01 & 443160.1 & 42.253 \\
\hline 6.5 & 3.53 & 6.62 & 2.71 & 5.62 & 183.232 & 1.3546 \\
\hline 7 & 3.8 & 4.43 & 3.15 & 4.12 & 2.893 & 0.563 \\
\hline 7.5 & 4.35 & 3.74 & 4.35 & 3.74 & 0.357 & 1 \\
\hline 8 & 4.62 & 4.46 & 4.62 & 4.46 & 0.763 & 1 \\
\hline
\end{tabular}
S1 shows the DFT parameters to calculate the ratios of rate constants.

Table S1. DFT extracted values used to calculate the kinetics parameters.

For $\mathrm{Na}^{+}$, the normalized on and off rate constant ratios were used as fitting parameters. The simulation from Figure 3 (main text) uses $r_{\mathrm{on}, \mathrm{Na}}=3.5 \mathrm{E} 0$ and $r_{\mathrm{off}, \mathrm{Na}^{+}}=4.5 \mathrm{E}-3$. To minimize the number of fitting parameters, the on and off prefactors were chosen to be the same equivalent value $\left(A_{\mathrm{on}} k_{\mathrm{on}, C l}=A_{\mathrm{off}} k_{\mathrm{off}, C l}=1 \mathrm{E}-2\right)$ and $\beta$ equal to 0.5 . 


\section{S3 Summary of the parameters in the multi species kinetics model}

In this section, we present a complete list of the parameters utilized in the simulation for Figure 3 in the main text.

Table S2. Numerical parameters used in the numerical simulation.

\begin{tabular}{|c|c|c|}
\hline \multicolumn{3}{|c|}{ Porous electrode and spacer geometric parameters } \\
\hline Parameter & Value & Notes \\
\hline $\mathrm{p}_{\mathrm{mi}}$ & 0.3 & Average micropore porosity of electrode \\
\hline $\mathrm{p}_{\mathrm{Ma}}$ & 0.65 & Average macropore porosity \\
\hline $\mathrm{p}_{\text {Sep }}$ & 0.34 & Average spacer porosity \\
\hline $\mathrm{A}\left(\mathrm{cm}^{2}\right)$ & 22.4 & Projected area of the porous electrode \\
\hline $\mathrm{L}_{\mathrm{el}}(\mathrm{mm})$ & 0.4 & Thickness of the porous electrode \\
\hline $\mathrm{L}_{\text {sep }}(\mathrm{mm})$ & 0.09 & Thickness of the spacer \\
\hline \multicolumn{3}{|c|}{ CDI cell parameters } \\
\hline Parameter & Value & Notes \\
\hline$C_{s t}\left(\mathrm{~F} / \mathrm{m}^{3}\right)$ & 200E6 & Capacitance in the stern layer \\
\hline$R_{S}(\Omega)$ & 1 & Series resistance \\
\hline$Q(\mathrm{~mL} / \mathrm{min})$ & 2 & Flow rate \\
\hline$V_{\text {mix }}(\mathrm{mL})$ & 1 & Mixed reactor volume (Not total cell volume) \\
\hline \multicolumn{3}{|c|}{ Charging discharging parameters } \\
\hline Parameter & Value & Notes \\
\hline$V_{\max }(\mathrm{V})$ & -0.8 & Constant voltage charge \\
\hline$V_{\min }(\mathrm{V})$ & 0.0 & Discharge voltage \\
\hline$t_{\mathrm{ch}}(\min )$ & 30 & Charging time \\
\hline$t_{\mathrm{dis}}(\min )$ & 30 & Discharge time \\
\hline
\end{tabular}




\section{S4 Simulations of classic $\mathrm{mD}$ model for CDI}

Figure $\mathrm{S} 1$ shows the numerical effluent normalized concentration of $\mathrm{NO}_{3}{ }^{-}$versus time obtained with a classic $\mathrm{mD}$ model for $\mathrm{CDI}$ for $\Delta H\left(\mu_{\text {att }}\right)$ equal to $-1,0,1,2,3$, and 3.5. The parameters of the simulation (Table S1) are identical to Figure 3 (main text). Although the feed concentration of $\mathrm{Cl}^{-}$is $10 x$ larger than $\mathrm{NO}_{3}^{-}$, the effluent profile of $\mathrm{NO}_{3}{ }^{-}$is indistinguishable to the effluent profile of $\mathrm{Cl}^{-}$. This is attributed to the selected values of $\Delta H\left(\mu_{\text {att }}\right)$ which are the same among species and cathode/anode.

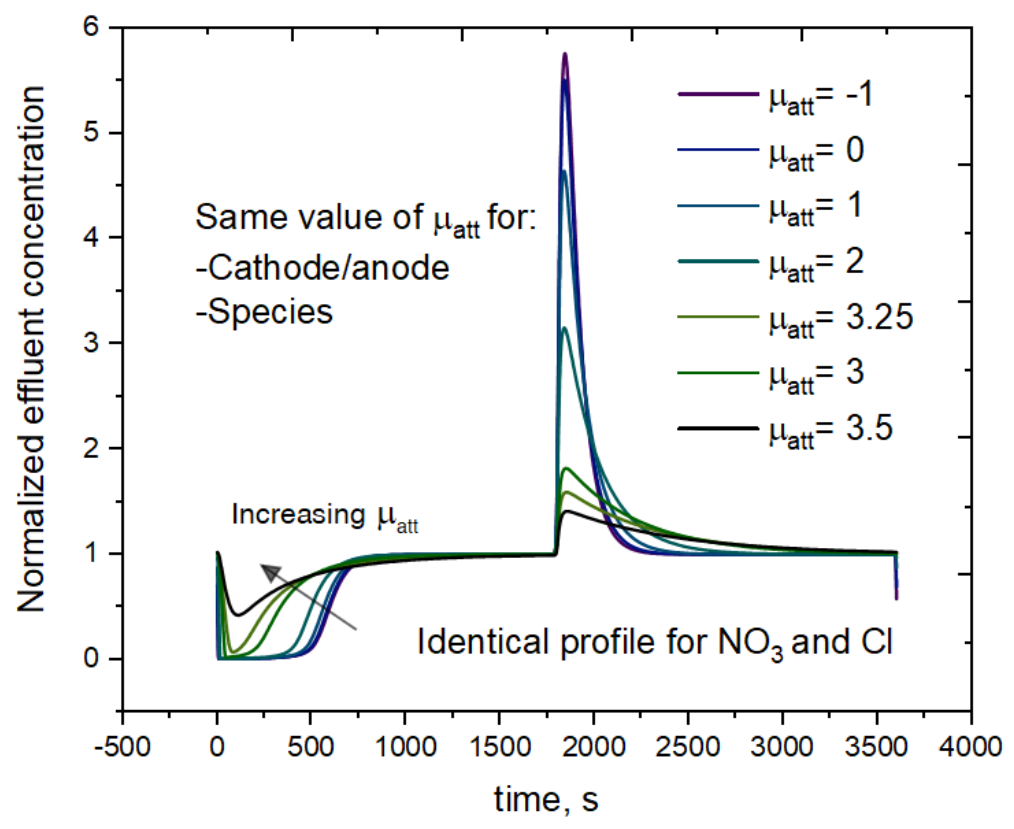

Figure S1. Normalized effluent concentration of $\mathrm{NO}_{3}{ }^{-}$(identical to $\mathrm{Cl}^{-}$), for a symmetric $\Delta H\left(\mu_{\text {att }}\right)$. The rest of the parameters of the simulation are available in Table S1.

Figure $\mathrm{S} 2$ shows the normalized effluent concentration of $\mathrm{NO}_{3}{ }^{-}$and $\mathrm{Cl}^{-}$with the classic $\mathrm{mD}$ model for $\Delta H_{\mathrm{NO}_{3}^{-}}=3.0, \Delta \mathrm{H}_{\mathrm{Cl}^{-}}=1.5$, and $\Delta \mathrm{H}_{\mathrm{Na}^{+}}=5.0$. In this non-symmetric case, the classic mD model captures a few of the features obtained with the kinetics model (Figure 3 main text). $\mathrm{Cl}^{-}$shows a typical adsorption and desorption behavior of a single ion process in CDI. However, unlike the kinetics model, the $\mathrm{mD}$ model cannot predict (1) the almost horizontal adsorption of $\mathrm{NO}_{3}{ }^{-}$at longer times, (2) the initial desorption peak of $\mathrm{NO}_{3}^{-}$, and (3) the slow initial adsorption of $\mathrm{NO}_{3}{ }^{-}$. Also, unlike the kinetics model, the desorption profile for $\mathrm{NO}_{3}{ }^{-}$obtained with the $\mathrm{mD}$ model shows a linear profile. 


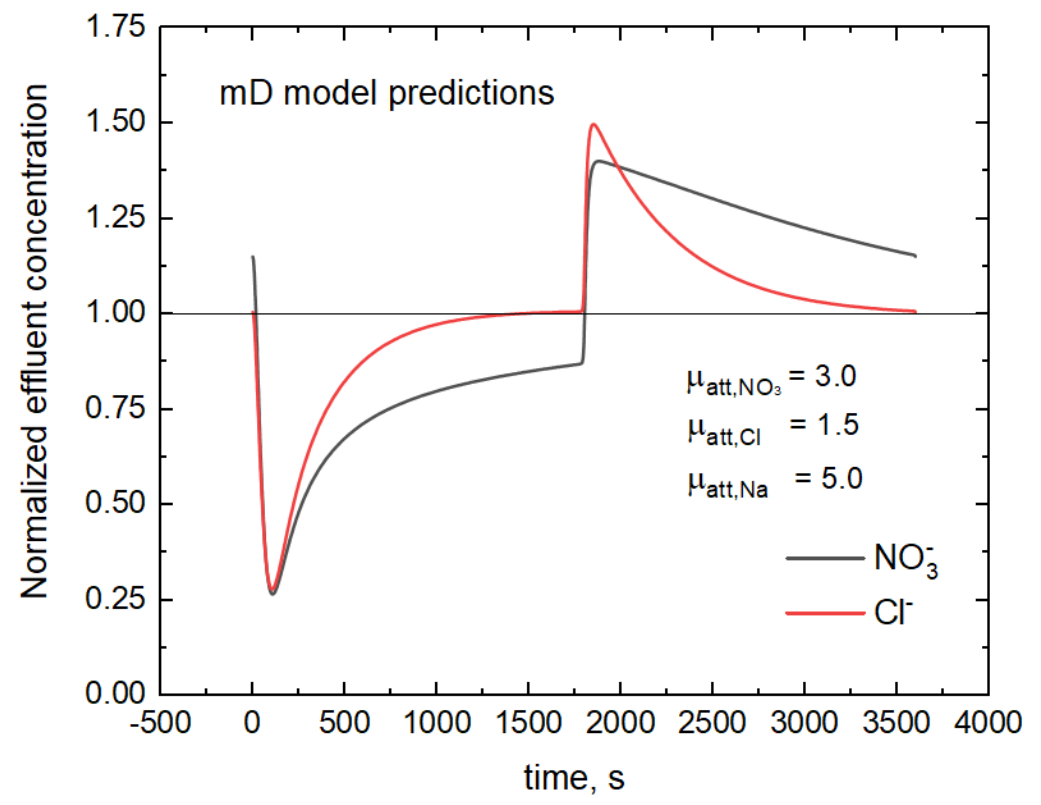

Figure S2. Normalized effluent concentration of $\mathrm{NO}_{3}{ }^{-}$and $\mathrm{Cl}^{-}$for $\Delta \mathrm{H}_{\mathrm{NO}_{3}^{-}}=3.0, \Delta \mathrm{H}_{\mathrm{Cl}^{-}}=1.5$, and $\Delta \mathrm{H}_{\mathrm{Na}^{+}}=5.0$. The rest of the parameters of the simulation are available in Table S1.

\section{S5 HCAM fabrication}

Hierarchical carbon aerogel monoliths (HCAM) electrodes were synthesized following previously reported procedures.(Biener et al. 2011; Baumann et al. 2008) The resorcinol-formaldehyde (RF) aerogel was carbonized at $950{ }^{\circ} \mathrm{C}$ for $3 \mathrm{~h}$ under $\mathrm{N}_{2}$. The carbon foam was subsequently activated with $3 \mathrm{~L} / \mathrm{min}$ of $\mathrm{CO}_{2}$ for $1 \mathrm{~h}$ and $30 \mathrm{~min}$ at $950{ }^{\circ} \mathrm{C}$ to obtain a $24.4 \%$ activation, based on the mass loss of the sample during activation from the starting carbon foam. Scanning electron microscope (SEM) micrographs of the HCAM were taken to examine the macroporosity of the electrodes using a Phenom ProX desktop platform (Figure S3). Pore size distribution (PSD) measurements of HCAM were performed by N2 sorption at $77 \mathrm{~K}$ with a Micromeritics ASAP 2020 using the N2DFT Model and AR-DFT Model for analysis (Figure S4). 

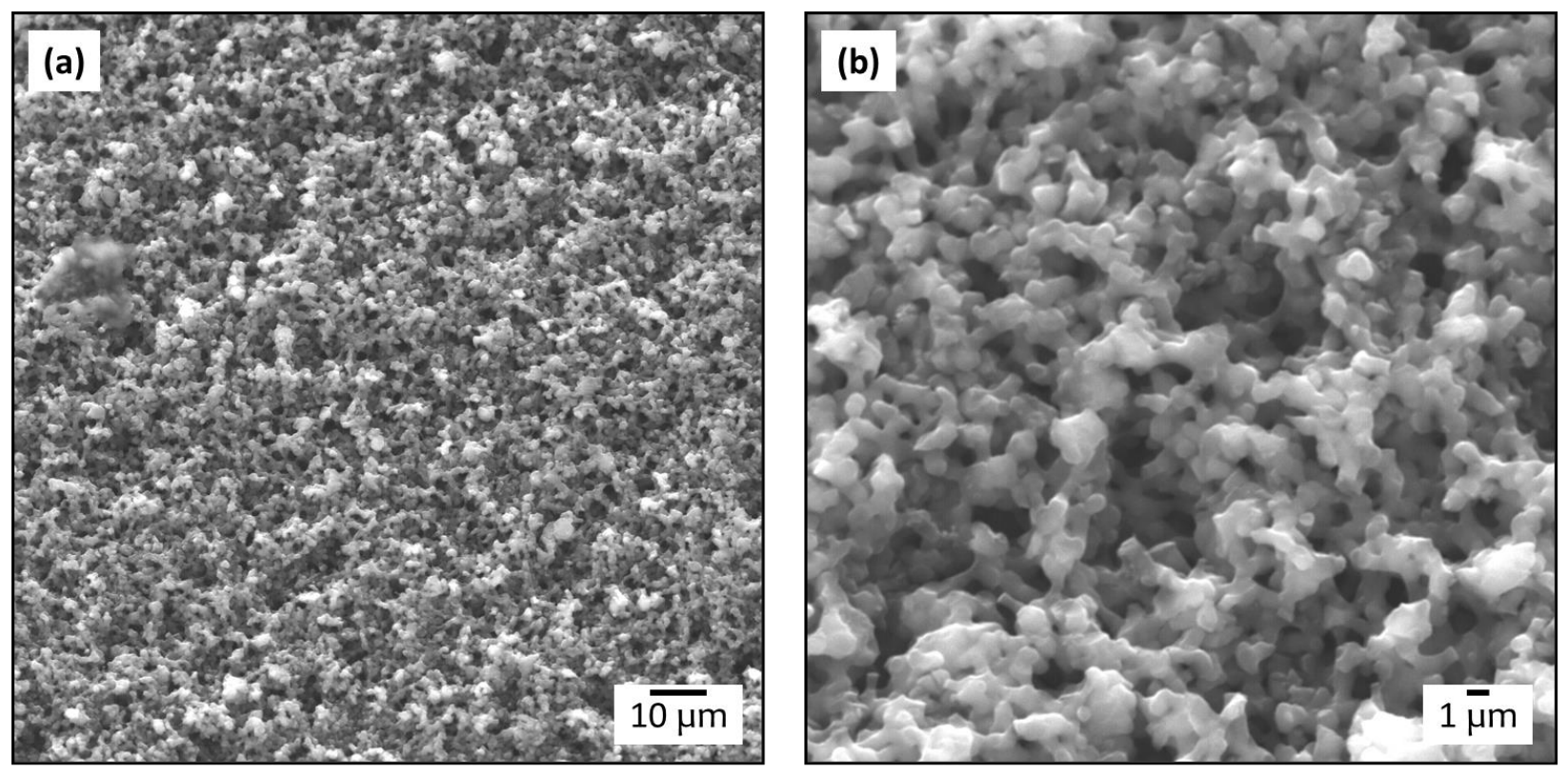

Figure S3. SEM micrographs of the cross section of HCAM electrodes after carbonization and activation at two different magnifications.

(a)

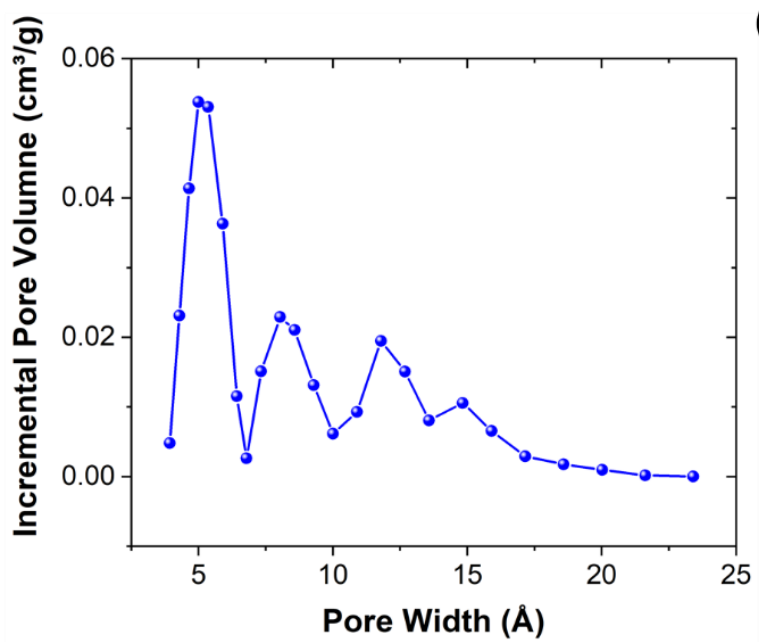

(b)

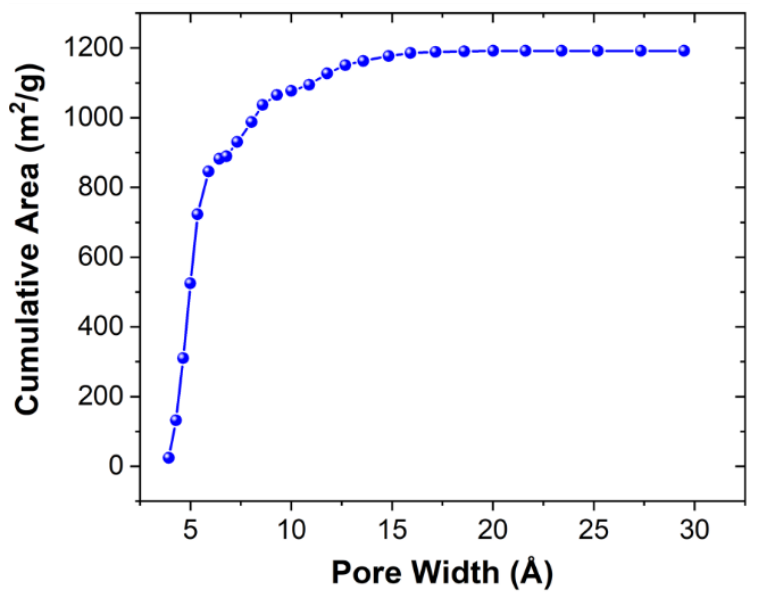

Figure S4. PSD from $\mathrm{N}_{2}$ adsorption measurements of HCAM electrodes. (a) Incremental pore volume as a function of pore width. (b) DFT cumulative surface area as a function of pore width.

FteCDI cells were assembled using two HCAM electrodes separated by a $90 \mu \mathrm{m}$ thick, 34\% porosity non-conductive polyester rectangular mesh slightly bigger than the HCAM electrodes (McMaster-Carr, 9218T73). Four strips of $25 \mu \mathrm{m}$ thick graphfoil were inserted into the cell for contacts. Finally, all the components of the fteCDI cell were sealed between laser-roughened 1 
mm thick polycarbonate header plates with tubulation ports with a UV-cure epoxy. (Hawks et al. 2018)

The resistance and capacitance of the just built cell was characterized by electrochemical impedance spectroscopy (EIS) and cyclic voltammetry (CV) respectively (Figure S5) using a 20 $\mathrm{mM} \mathrm{NaCl}$ solution at $3 \mathrm{~mL} / \mathrm{min}$ (BioLogic VSP-300 potentiostat, Watson Marlow, Falmouth, Cornwall UK). The feed solution was in closed-loop circulation with a $500 \mathrm{~mL}$ reservoir continuously purged with hydrated nitrogen.

(a)

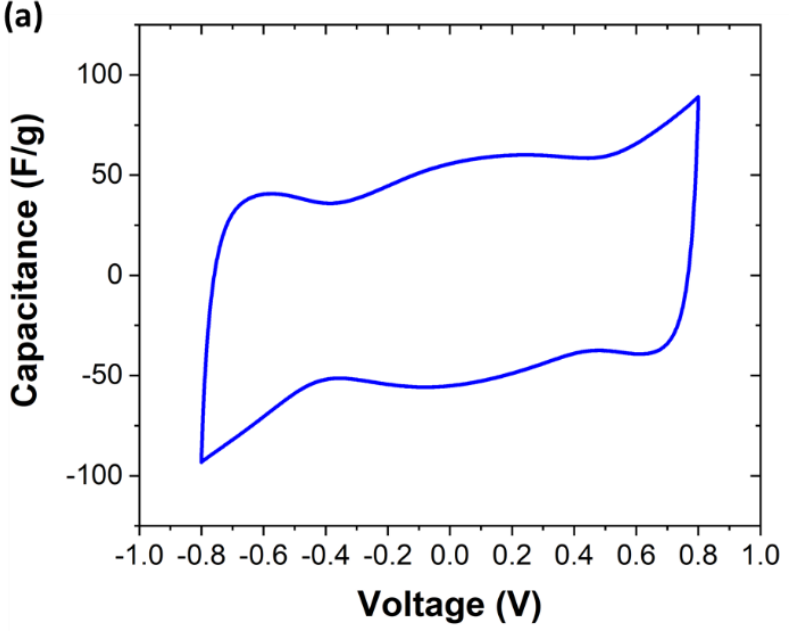

(b)

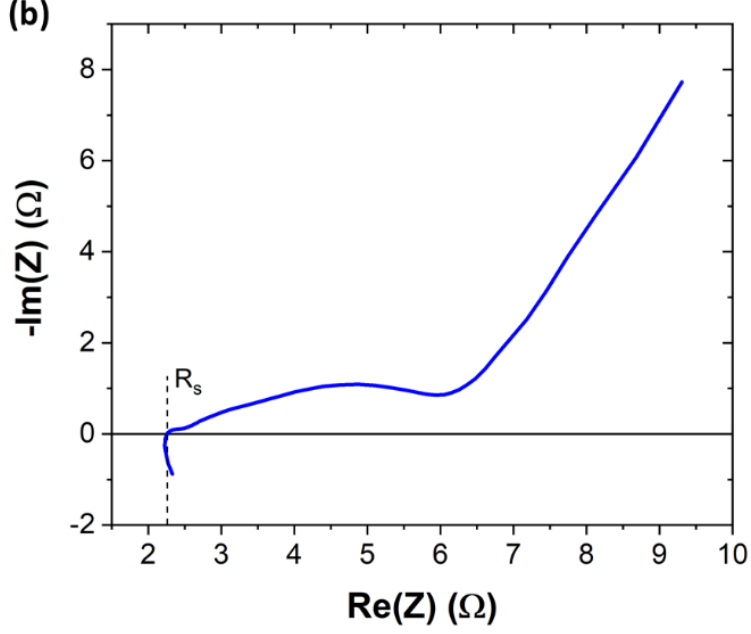

Figure S5. Electrochemical characterization of fteCDI cells using $20 \mathrm{mM} \mathrm{NaCl}$ as electrolyte, flow rate 3 $\mathrm{mL} / \mathrm{min}$. (a) Nyquist plots from EIS measurements, $700 \mathrm{kHz}$ to $5 \mathrm{mHz}$ at $0 \mathrm{~V}$ DC bias, 4-wire mode. (b) Cyclic voltammograms taken at $0.5 \mathrm{mV} / \mathrm{s}$.

\section{S6 Real time UV-vis measurements}

The concentrations of nitrate and chloride leaving the CDI cell as a function of time were measured by UV absorption through an in-line quartz flow cell (Hellma Suprasil quartz, pathlength $0.1 \mathrm{~mm}$, chamber volume $6.2 \mu \mathrm{L}$ ). The UV absorption setup consisted of two microspectrometers (Ocean Optics STS-UV-L-50-400-SMA STS, 190-600nm, 50um Slit, 400 Core/1 cm SMA Input) connected to a deuterium-tungsten light source (Ocean Optics DH-2000-S-DUV-TTL) via a bifurcated fiber optic cable (Ocean Optics extreme solarization-resistant QP450-0.25-XSR, 455 $\mu \mathrm{m})$. The flow-through cuvette was secured and aligned with the fiber optic cables using an Ocean Optics CUV-UV cuvette holder. A schematic of the setup is detailed in Fig. S6. 
Multiple spectrometers were used because we found that the deep UV portion of the deuterium lamp spectrum would drift in intensity throughout the course of an experiment. Thus, we used a reference spectrometer to make a live relative correction on a wavelength-by-wavelength basis throughout the experiment. Before each experiment, we measured a blank reference spectrum of pure de-ionized water (Milli-Q ultrapure 18.2 M $\mathrm{M}-\mathrm{cm}$ ) and proceeded to measure absolute absorbance as a function of time during CDI charge/discharge cycles.

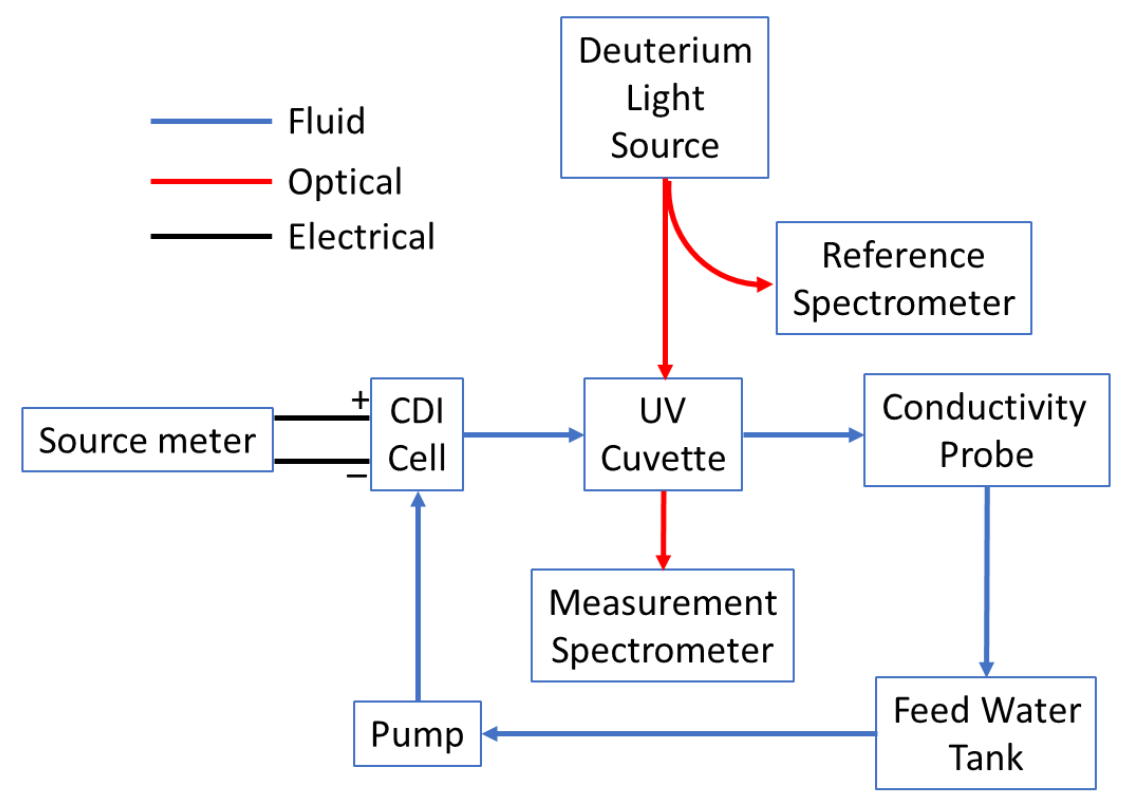

Figure S6. A schematic outline of the experimental setup used to detect nitrate and chloride adsorption selectivity over the course of charging/discharging cycles.

To deduce a molar concentration of nitrate or chloride from the absorbance profile, we measured a series of individual sodium nitrate and sodium chloride concentrations using standard solutions for ion chromatography (Sigma Aldrich). We made each concentration series by serial dilution, and the absorbance results are shown in Fig. S7. From the data in in Fig. S7 we can construct absorbance spectra of an arbitrary mixture of $\mathrm{NO}_{3}, \mathrm{Cl}$ ions within the concentration range measured by using cubic Hermite interpolation at each wavelength and summing the contributions of chloride and nitrate. 

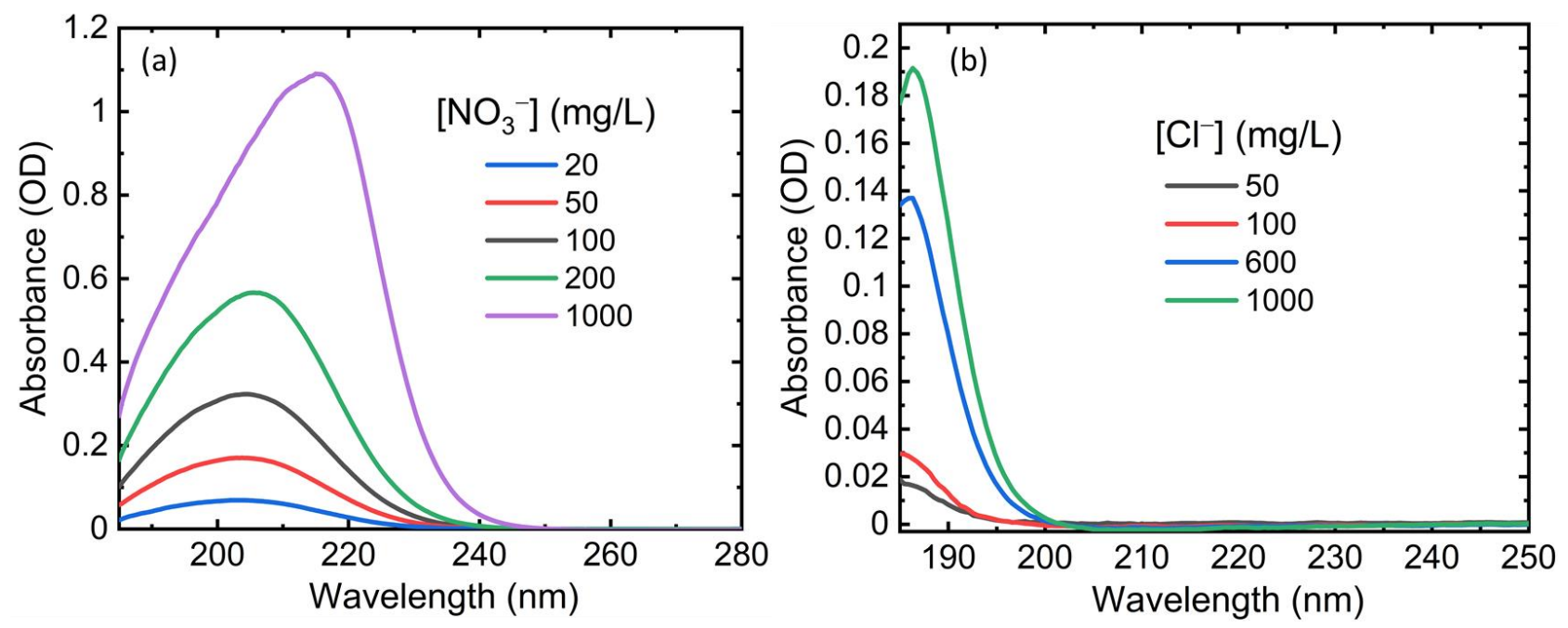

Figure S7. Absorbance spectra of different standard sodium nitrate (a) and sodium chloride (b) solutions in the UV absorbance setup of Fig S6. The pathlength in all measurements $100 \mu \mathrm{m}$. These standard spectra were ultimately used in an interpolation scheme to extract the unknown concentrations of a mixture of sodium nitrate and chloride.

In principle, this is all that is needed to obtain the absolute chloride and nitrate concentrations in the effluent stream. However, in order to more confidently determine the absolute ion concentrations, we coupled conductivity probe measurements to the absorbance spectra fits using the open source MATLAB program limcond to compute a predicted electrolyte conductivity. ${ }^{1}$ With appropriate weighting and a uniform time shift to account for the physical separation of the conductivity probe and UV flow cell, we are able to fit recorded absorbance spectra to obtain an estimate of the individual nitrate and chloride concentrations. Examples of these fits are given in Fig. S8, showing excellent agreement between measured and fit absorbance and conductivity. Using this approach, we were able to measure effluent nitrate and chloride concentration profiles as a function of applied constant voltage and polarity. 


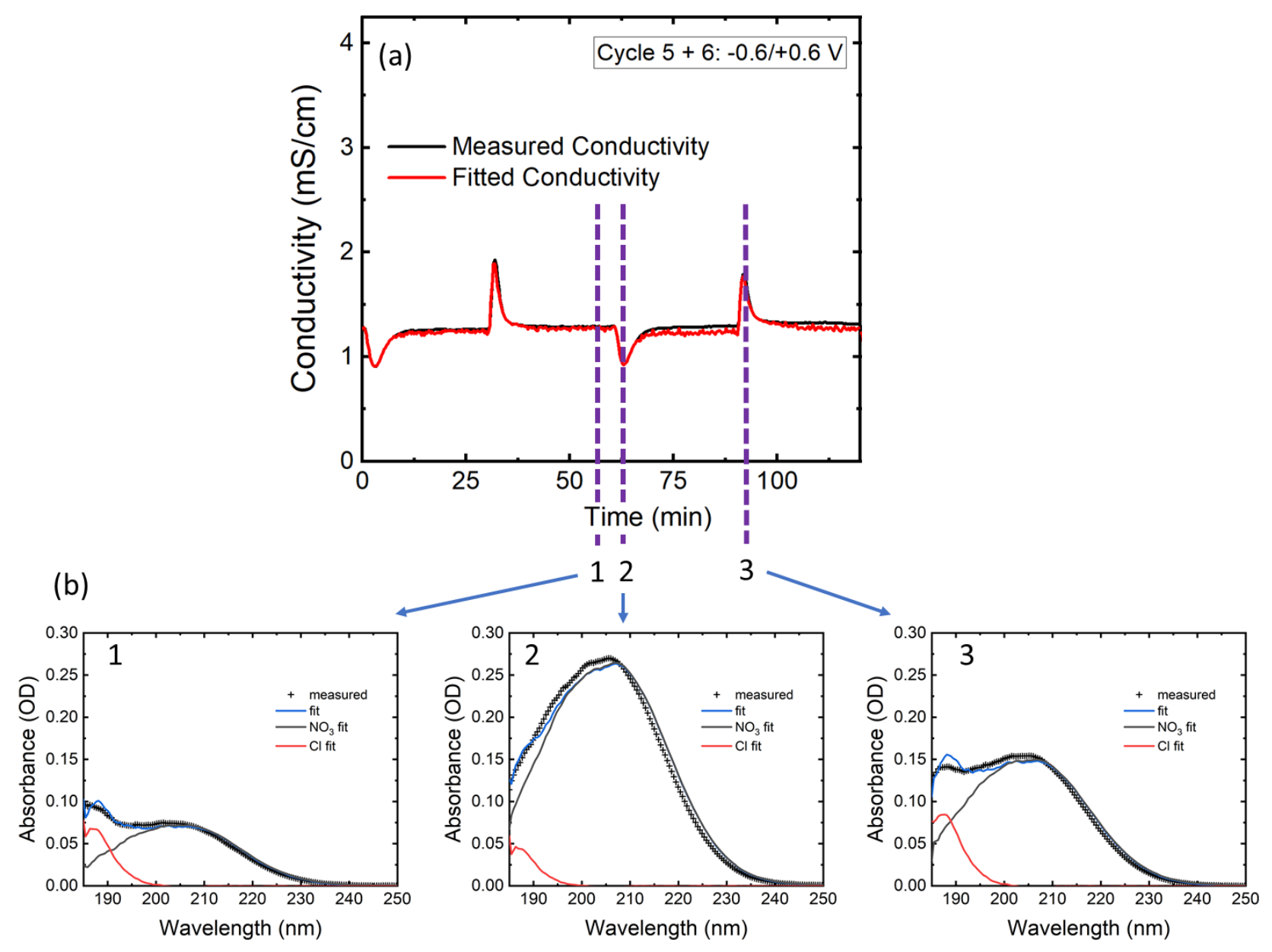

Figure S8. Example fits of conductivity (a) and absorbance (b) during alternating polarity zero-volt discharge constant voltage CDI cycles. The marked positions in measured conductivity show the corresponding absorbance plots. The excess of nitrate at location 2 is due to the inversion peak observed with nitrate discussed in the main paper and below. 

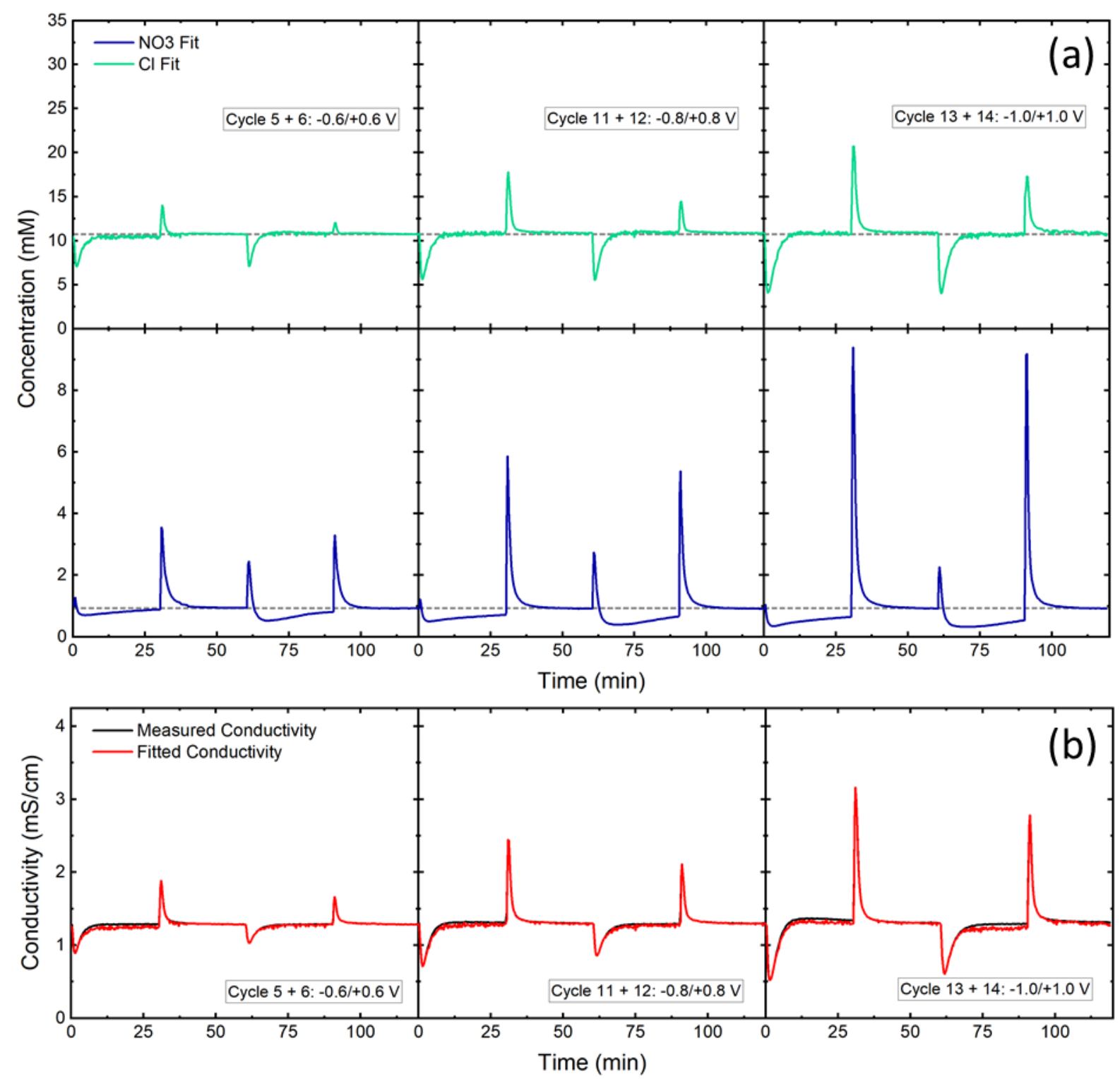

Figure S9. (a) Individual nitrate and chloride effluent concentration profiles as a function of time and voltage for constant voltage alternating polarity zero-volt discharge CDI. (b) The corresponding measured and predicted effluent conductivity showing excellent agreement assuming the nitrate and chloride concentrations in (a). The Dashed grey line in (a) represents the feed concentration. The flow rate was 4 $\mathrm{ml} / \mathrm{min}$. 
S7 Two-dimensional potential energy surface (2D-PES) as a function of Y,Z coordinates from DFT simulation.
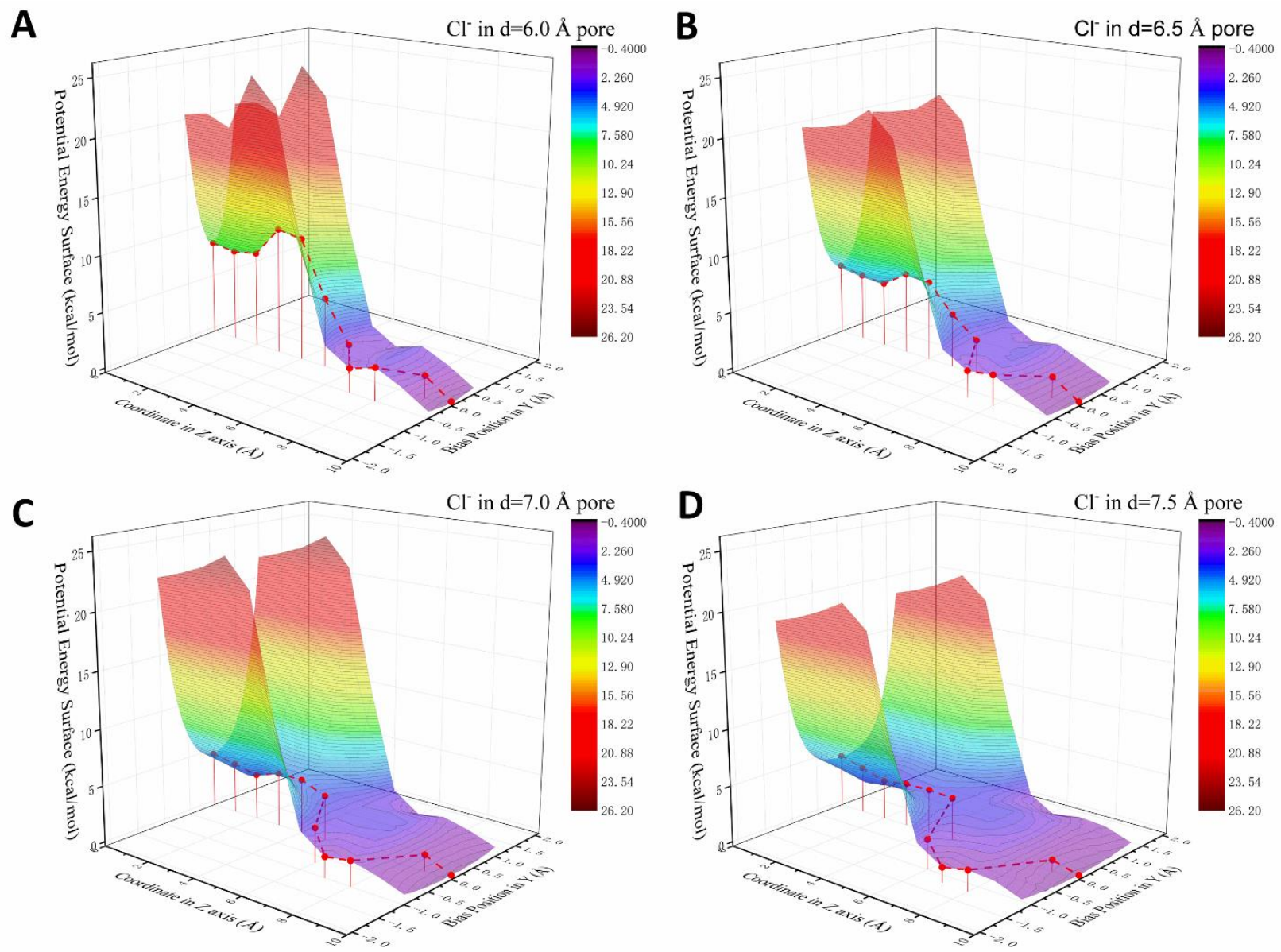

Figure S9. DFT simulation of 2D-PES for $\mathrm{Cl}^{-}$from single point energy scanning at the interfacial region for the nano-pores with different width: (a) 6.0, (b) 6.5, (c) 7.0, (d) 7.5 angstrom. The red dots denote the lowest energy in $\mathrm{Y}$ axis and red dashed line denotes the preferable pathway. 
A

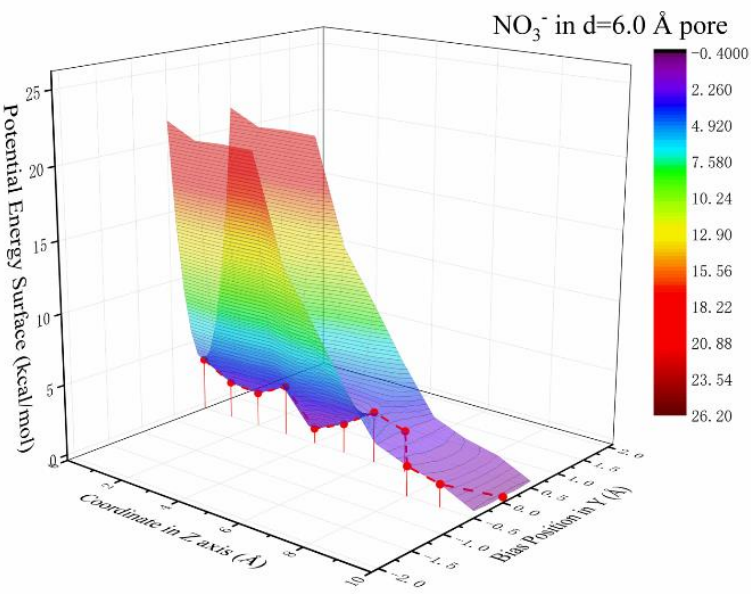

C

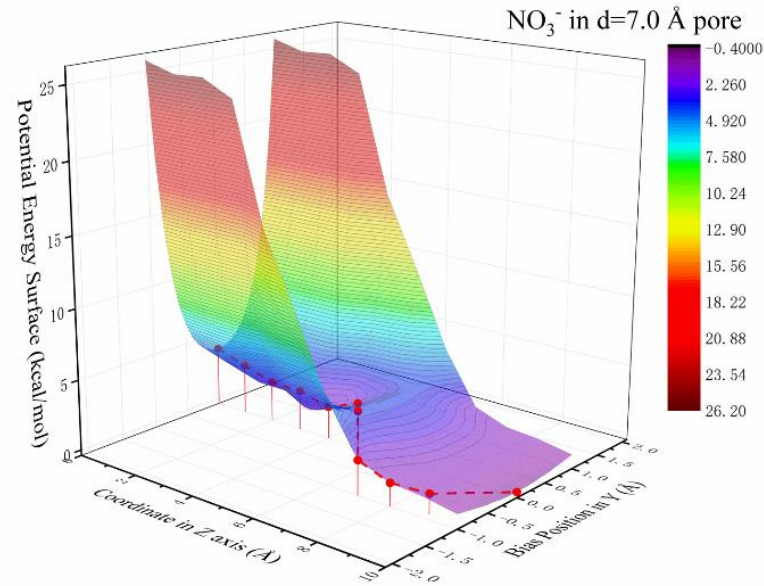

B
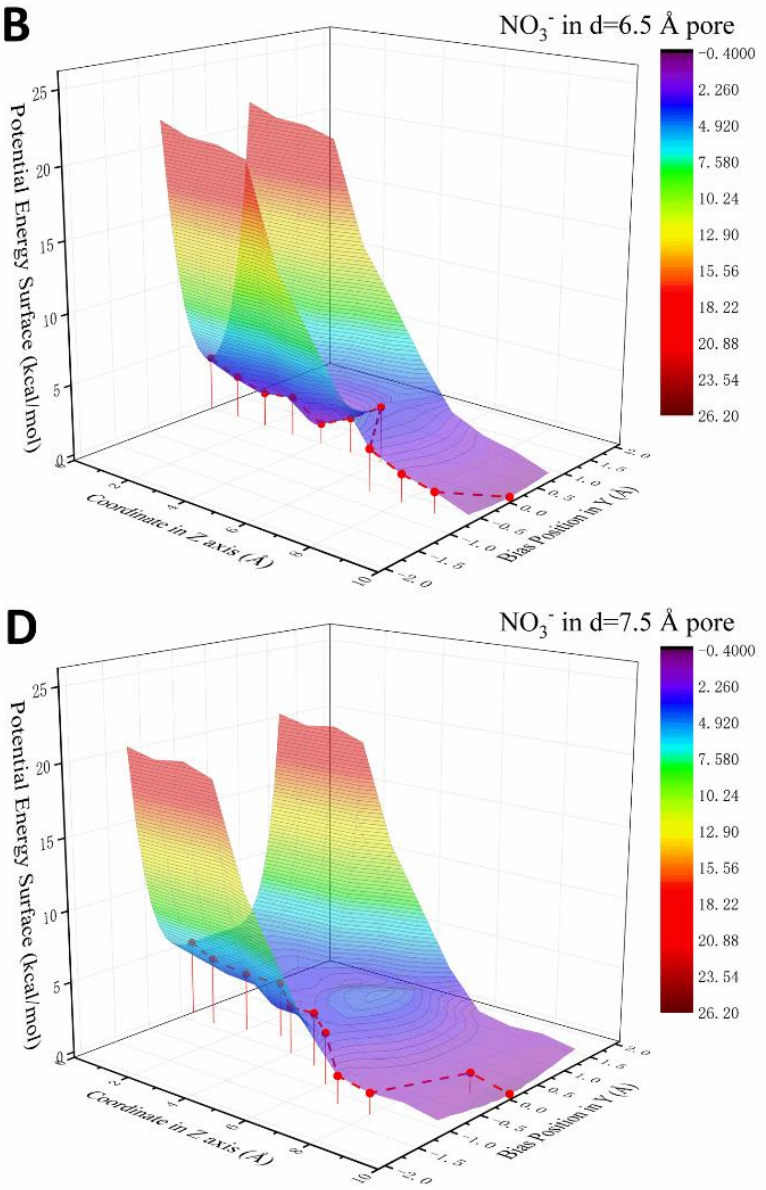

Figure S10. DFT simulation of 2D-PES for $\mathrm{NO}_{3}{ }^{-}$from single point energy scanning at the interfacial region for the nano-pores with different width: (a) 6.0, (b) 6.5, (c) 7.0, (d) 7.5 angstrom. The red dots denote the lowest energy in $\mathrm{Y}$ axis and red dashed line denotes the preferable pathway. $\mathrm{NO}_{3}{ }^{-}$molecule is parallel to the graphene sheet.

\section{References}

Baumann, Theodore F., Marcus A. Worsley, T. Yong-Jin Han, and Joe H. Satcher. 2008. "High Surface Area Carbon Aerogel Monoliths with Hierarchical Porosity." Journal of NonCrystalline Solids 354 (29): 3513-15. https://doi.org/10.1016/j.jnoncrysol.2008.03.006.

Biener, Juergen, Michael Stadermann, Matthew Suss, Marcus A. Worsley, Monika M. Biener, Klint A. Rose, and Theodore F. Baumann. 2011. "Advanced Carbon Aerogels for Energy Applications." Energy \& Environmental Science 4 (3): 656-67. https://doi.org/10.1039/C0EE00627K.

Hawks, Steven A., Jennifer M. Knipe, Patrick G. Campbell, Colin K. Loeb, McKenzie A. Hubert, Juan G. Santiago, and Michael Stadermann. 2018. "Quantifying the Flow Efficiency in Constant-Current Capacitive Deionization." Water Research 129 (February): 327-36. https://doi.org/10.1016/j.watres.2017.11.025. 